GU J Sci, Part C, 6(4): 919-927 (2018)

Gazi Üniversitesi
Fen Bilimleri Dergisi
PART C: TASARIM VE TEKNOLOJI
http://dergipark.gov.tr/gujsc

\title{
PEG-400 Destekli Alümina Sentezi, Karakterizasyonu ve Morfolojik Özelliklerin İncelenmesi
}

\author{
Sema VURAL ${ }^{1, *}$, Özlem SARI ${ }^{2}$ \\ ${ }^{1}$ Konya Necmettin Erbakan Üniversitesi, Seydişehir A.C. Mühendislik Fakültesi, Metalürji ve Malzeme Mühendisliği Bölümü, 42370, \\ Seydişehir/KONYA \\ ${ }^{2}$ Konya Necmettin Erbakan Üniversitesi, Fen Bilimleri Enstitüsü, Makine Mühendisliği ABD, 42140, Meram/KONYA
}

$\underline{\mathbf{O} z}$

Makale Bilgisi

Başvuru: 07/05/2018

Düzeltme: 15/09/2018

Kabul: $14 / 10 / 2018$

Anahtar Kelimeler

$\alpha$-Alümina

PEG-400

Hidrotermal Sentez

Morfolojik Etki

Keywords

$\alpha$-Alümina

PEG-400

Hydrothermal Synthesis

Morphological Effect
$\mathrm{Bu}$ çalışmada hidrotermal sentez yöntemi kullanılarak PEG-400 destekli $\alpha$-alümina $\left(\alpha-\mathrm{Al}_{2} \mathrm{O}_{3}\right)$ sentezi başarılı şekilde gerçekleştirilmiştir. Yapı düzenleyici ajan olarak kullanılan PEG-400'ün parçacık boyutuna etkileri araştııılmıştır. Sentezlenen tozların yapısal karakterizasyonu XRD, Raman ve FTIR yöntemleri kullanılarak gerçekleştirilmiştir. Termal özelliklerin araştırılmasında TGA yöntemi kullanılmıştır. Morfolojik özellikler ise SEM yöntemi kullanılarak araştırılmıştır. Çalışmanın sonuçları yapı düzenleyici ajan kullanılmadan gerçekleştirilen deneyle karşılaştırıldığında daha küçük boyutlarda saf $\alpha-\mathrm{Al}_{2} \mathrm{O}_{3}$ elde edildiğini göstermektedir.

\section{PEG-400 Supported Alumina Synthesis, Characterization and Investigation of Morphological Properties}

\begin{abstract}
In this study, $\alpha$-alümina structures are successfully prepared via hydrothermal synthesis supported with PEG-400. The effect of the PEG-400 as structure directing agent on the particle size is investigated. The structural characterization of the prepared powders is carried out using XRD, Raman and FTIR techniques. TGA analysis technique is used for the investigation of the thermal properties of the powders. Morphological properties are investigated using SEM technique. Obtained results show that comparing with the experiment without the use of the structure directing agent, pure $\alpha-\mathrm{Al} 2 \mathrm{O} 3$ was obtained in smaller size.
\end{abstract}

\section{GİRIŞ (INTRODUCTION)}

Alümina, mekanik, elektriksel, termal ve optik özellikleri nedeniyle endüstriyel kimyada kullanılan en önemli inorganik maddelerden biridir [1]. Sahip olduğu üstün özelliklerinden dolayı kataliz, katalizör yatağı uygulamaları, yüzey kaplamaları, refrakter madde üretimi, optik ve lazerler gibi pek çok önemli uygulamada kullanılmaktadır [2-4]. Alümina kristal yapılarına göre genel olarak iki grupta toplanabilir. Bunlar oksijen anyonlarının kristal yapıdaki konumlanmalarına göre yüzey merkezli kübik sistem (FCCFace Centered Cubic) ve hekzagonal kübik sistem (HCP- Hexagonal Cubic Packet) şeklindedir. Katyonun kristal yapı içerisinde dağılımı bu alt grupların pek çok alümina polimorflarına sahip olmasına neden olur. FCC kristal düzenlenmesindeki alümina formları gama $(\gamma-)$, eta $(\eta-)$, delta $(\delta$-) ve teta $(\theta-)$ formları iken, HCP kristal düzenlenmesindeki alümina formları çi $(\chi-)$, kapa $(\kappa-)$ ve alfa $(\alpha-)$ alümina yapılarıdır. Alüminanın kararlı tek fazı yüksek termal kararlılık, kimyasal direnç ve sertliğe sahip alfa formudur ve $1230^{\circ} \mathrm{C}$ üzerindeki kalsinasyon işlemleriyle elde edilir [5,6]. Bohmit yapısı (AlOOH), alfa alümina sentezinde en çok tercih edilen başlangıç maddesidir. Literatürde faz dönüşüm sıcaklıkları ile ilgili çeşitli sicaklıklar verilmekle birlikte genel kabul: Bohmit $\rightarrow \gamma\left(300^{\circ} \mathrm{C}\right) ; \gamma \rightarrow \delta\left(850^{\circ} \mathrm{C}\right) ; \delta \rightarrow \theta\left(1100^{\circ} \mathrm{C}\right) ; \theta \rightarrow \alpha$ $\left(\geq 1200^{\circ} \mathrm{C}\right)$ şeklinde gösterilebilir [7-10].

$\alpha$-alümina sentezinde mekanik öğütme, buhar fazı reaksiyonu, çöktürme, sol-jel, hidrotermal sentez ve yakma metodu gibi çeşitli yöntemler bilinmektedir [11-17]. Bu yöntemlerin hemen hepsinde kendine has 
sınırlayıcı özellikler bulunmaktadır. Örneğin; sol-jel yönteminde başlangıç malzemesi olarak kullanılan alkoksitlerin maliyeti yüksektir ve proses uzun jelleşme süreçlerine ihtiyaç duyar. Çöktürme yöntemi hem karmaşık olmasından hem de uzun yıkama ve olgunlaştırma süreçlerine ihtiyaç duymasından dolayı alternatiflerin en iyisi değildir. Hidrotermal yöntem ise çok miktarda ve yüksek kalitede kristaller elde edilebilmesi nedeniyle bu yöntemlerden en çok tercih edilenidir [18].

Kimyasal yöntemler farklı özelliklere sahip çeşitli kristallerin sentezinde genellikle 1lımlı şartlarda gerçekleştirilen, basit ve bu nedenle de vazgeçilmez yöntemlerdir. Bir kimyasal sentezde parçacık oluşumu çekirdeklenme, parçacık büyümesi ve sonlanma olmak üzere üç basamakta gerçekleşir. Burada en önemli basamağı oluşturan Oswald olgunlaşması adı verilen parçacık büyümesi basamağıdır. Oswald olgunlaşması iyonlar halinde çözeltide bulunan parçacıkların daha büyük parçacıklar oluşturmak üzere bir araya gelmesidir. Büyüyen parçacıkların çözelti içerisinde çözünürlüğünün azalması parçacık büyümesini sonlandırır [19]. Kimyasal bir sentez sırasında reaksiyon ortamında büyüme basamağını sınırlandıracak ve reaksiyona herhangi bir katkıda bulunmayacak bir başka maddenin varlığı parçacık boyutunun da sınırlandırılmasına neden olur. Bu amaçla çeşitli yüzey aktif maddelerle kullanımı, polimer, silika, karbon ve metallerle kaplama yöntemleri çok kullanılan yöntemler arasındadır [20].

$\mathrm{Bu}$ çalışmada; henüz literatürde rapor edilmemiş PEG-400 destekli hidrotermal $\alpha$-Al2O3 sentezi gerçekleştirilmiştir. Yapı düzenleyici olarak kullanılan PEG-400, reaksiyon ortamına farklı miktarlarda katkılanarak parçacık morfolojisine etkileri araştırılmıştır. Elde edilen tozların yapısal özellikleri X-1şını kırınımı (XRD), Raman ve Infrared (FTIR) spektroskopileri yardımıyla gerçekleştirilmiştir. Elde edilen yapıların termal özelliklerinin belirlenmesinde termogravimetrik analiz (TGA) kullanılmıştır. Morfolojik özelliklerin belirlenmesinde ise taramalı elektron mikroskobu (SEM) tekniğinden yararlanılmıştır.

\section{DENEYSEL KISIM (EXPERIMENTAL)}

Alümina sentezinde başlangıç maddesi olarak \%99 saflıktaki $\mathrm{Al}\left(\mathrm{NO}_{3}\right)_{3} .9 \mathrm{H}_{2} \mathrm{O}$, yapı düzenleyici ajan olarak polietilen-400 (PEG-400) ve hidroliz ajanı olarak da \%35'lik amonyak çözeltisi kullanılmıştır. Bütün reaktifler ticari firmalardan temin edilmiş ve ileri saflaştırmalar yapılmadan deneylerde kullanılmıştır. Başlangıç çözeltisinin hazırlanmasında de-iyonize su kullanılmıştır.

PEG-400 destekli alümina sentezi hidrotermal sentez yöntemiyle gerçekleştirilmiştir. Öncelikle, $\mathrm{Al}\left(\mathrm{NO}_{3}\right)_{3} \cdot 9 \mathrm{H}_{2} \mathrm{O}$ ile 0,3 M'lik başlangıç çözeltisi hazırlanmış ve çözelti oda sıcaklığında 1 saat karıştırılmıştır. PEG-400 çözeltileri belli derişimde hazırlanıp oda sıcaklığında 1 saat karıştırıldıktan sonra kütlece $\% 1, \% 3$ ve \%5'lik karışımlar oluşturacak şekilde başlangıç çözeltisine eklenmiştir. Homojen karışımın sağlanması için karışım 1 saat daha oda sıcaklığında karıştırılmıştır. \%35’lik

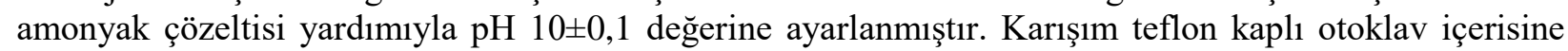
aktarılarak $180^{\circ} \mathrm{C}^{\prime}$ de 9 saat reaksiyonun gerçekleşmesi sağlanmıştır. Reaksiyon sonunda oda sıcaklığına soğutulan reaksiyon karışımı 12000 min-1'de santrifüj yardımıyla çöktürülmüştür. Elde edilen katı birkaç kez saf su ile yıkanarak saflaştırılmıştır. Ürün vakum etüvünde $40^{\circ} \mathrm{C}$ 'de 24 saat kurutulduktan sonra ögütülerek 3 saat $1200^{\circ} \mathrm{C}$ 'de kalsine edilmiştir. Sentezlere ilişkin reaksiyon şeması Şekil 1'de gösterilmektedir. 


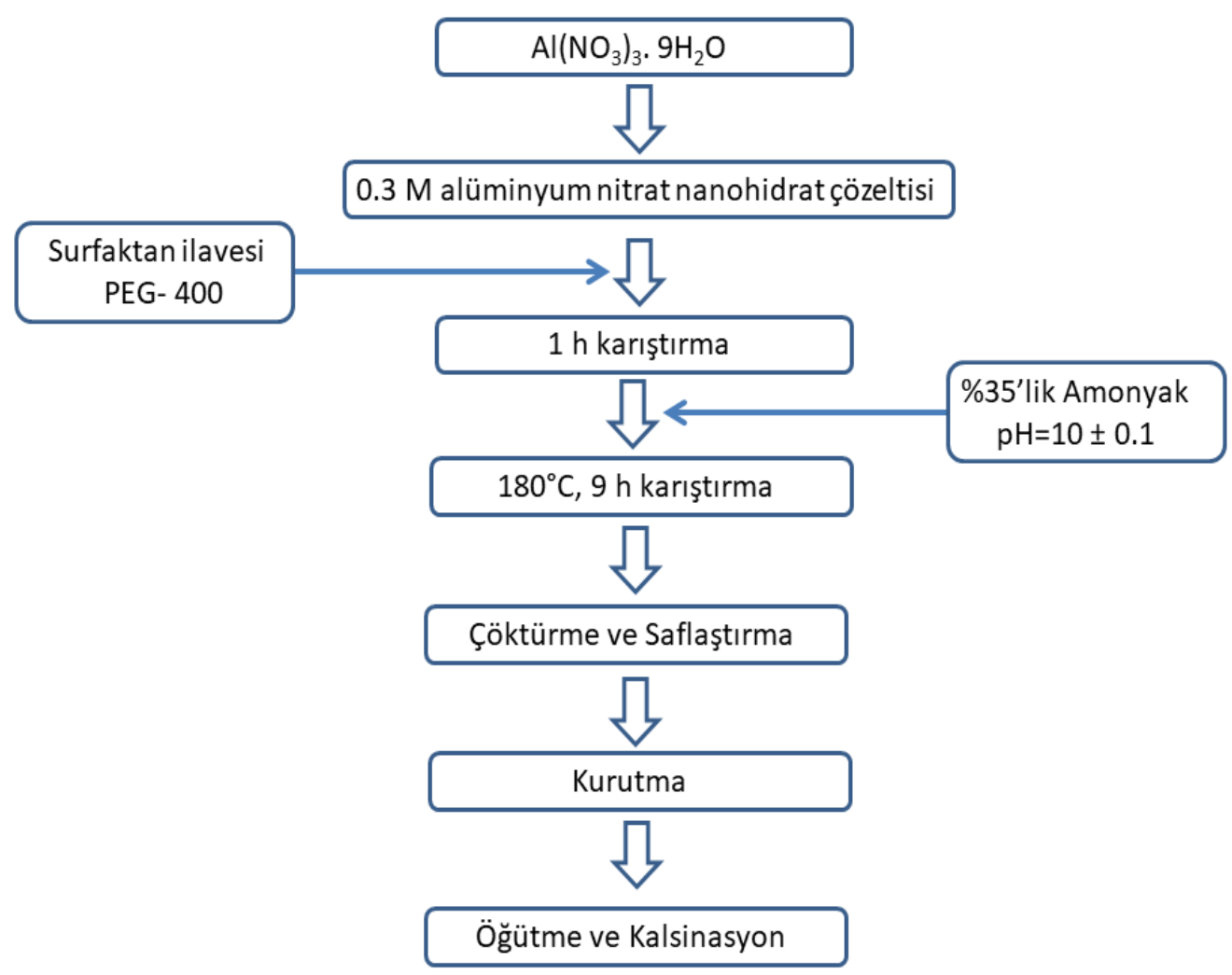

Şekil 1. $\mathrm{Al}_{2} \mathrm{O}_{3}$ sentezinin şematik gösterimi

Örneklerin X-1şını kırınım analizleri Rigaku Rad B-Dmax II toz difraktometre kullanılarak gerçekleştirilmiştir. $2 \theta$ değerleri $0,04^{\circ}$ 'lik basamaklar halinde $\mathrm{Cu} \mathrm{K \alpha}(\lambda=1.5405 \AA)$ 1şıması kullanılarak $20^{\circ}$ ile $110^{\circ}$ arasında alınmıştır. XRD analizi $4^{\circ} / \mathrm{min}^{\prime}$ lik tarama hızıyla gerçekleştirilmiştir. Kurutulan örnekler, pik değerlerindeki sapmaları ve örnek kalınlığından kaynaklanabilecek pik genişlemesi gibi durumları en aza indirmek amaciyla $30( \pm 2) \mathrm{mg}$ 'lik miktarlarda, $5 \mathrm{~cm}^{2}$ 'lik alana ince bir tabaka şeklinde yayılarak analize hazırlanmıştır. Yine yapısal karakterizasyonda Renishaw Invia Reflex Confocal (x100 objektif) Raman Spektrometre ile 1800 çizgi/mm 1zgara ve $200 \mathrm{~mW}$ lazer gücünde $532 \mathrm{~nm}$ eksitasyon enerjisi ile çalışılmıştır. Yine yapısal karakterizasyonda kullanılan Infrared spektrumları ATR metoduyla $4000-450 \mathrm{~cm}^{-1}$ aralığında, Nicolet iS5 FTIR spektrometre kullanılarak elde edilmiştir. Termogravimetrik analiz (TGA), Shimadzu TGA-50 kullanılarak $10^{\circ} \mathrm{C} / \mathrm{min}$ hızla ve $10 \mathrm{mg}$ örnek kullanılarak oksijen ortamında gerçekleştirilmiştir. Morfolojik özelliklerin belirlenmesinde Leo-Evo 40xVP taramalı elektron mikroskobu (SEM) kullanılmıştır. Analizlerde 3 ile $30 \mathrm{keV}$ aralığında elektron enerjisi kullanılmış olup, bütün numunelerde 1şın örnek yüzeyine normal gönderilmiş ve ölçüm $100 \mathrm{~s}$ olarak gerçekleştirilmiştir. Bütün numunelere SEM analizlerinden önce $\mathrm{Au} / \mathrm{Pd}$ kaplaması yapılmıştır.

\section{SONUÇ (RESULT)}

Hidrotermal reaksiyon sonrasında elde edilen bohmit yapısının karakterizasyonunda XRD yöntemi tercih edilmiştir. Şekil 2, sentez sonrası elde edilen bohmit yapılarına ilişkin XRD spektrumlarını göstermektedir. Spektrumda 28, 38 ve 49 derecelerde gözlenen şiddetli pikler bohmit yapısına ait karakteristik (120), (031) ve (200) pikleridir (JCPDS 00-21-1307) [21]. Yapıya ilişkin diğer karakteristik pikler spektrum üzerinde gösterilmiştir. 


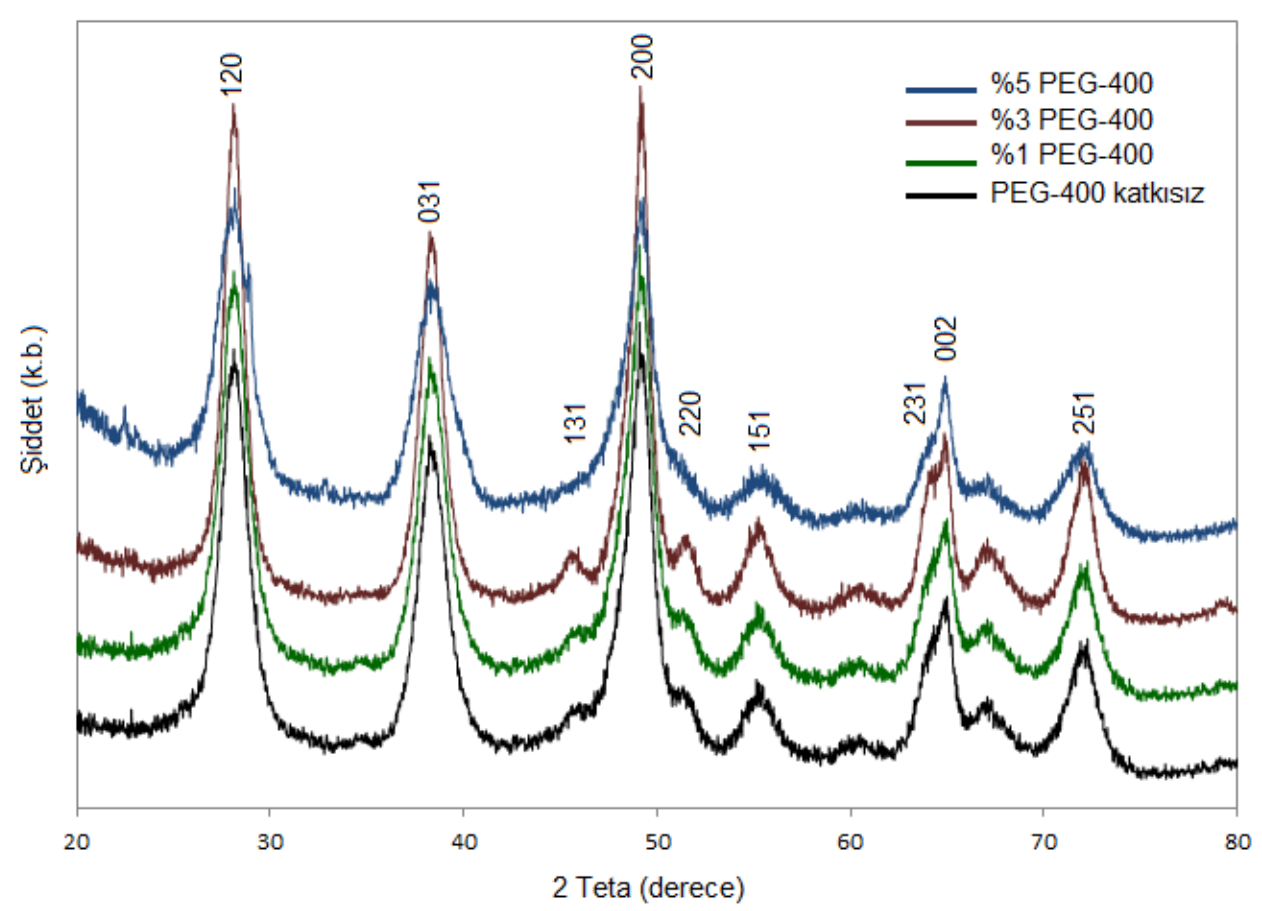

Şekil 2. Bohmit (AlOOH) yapısina ait XRD spektrumu

Raman spektroskopi tekniği malzemelerin yapı, kompozisyon ve faz analizinde yaygın olarak kullanılmaktadır. Şekil 3 sentezlenen $\alpha$-Alümina yapılarının Raman spektrumunu vermektedir. $\alpha-\mathrm{Al}_{2} \mathrm{O}_{3}$ yapısına ilişkin Raman optik bantları:

$$
2 \mathrm{~A} 1_{\mathrm{g}}+2 \mathrm{~A} 1_{\mathrm{u}}+3 \mathrm{~A} 2_{\mathrm{g}}+2 \mathrm{~A} 2_{\mathrm{u}}+5 \mathrm{E}_{\mathrm{g}}+4 \mathrm{E}_{\mathrm{u}}
$$

şeklindedir. Burada $2 \mathrm{~A} 1_{\mathrm{g}}+5 \mathrm{E}_{\mathrm{g}}$ Raman aktif modlar, $2 \mathrm{~A} 2_{\mathrm{u}}+4 \mathrm{E}_{\mathrm{u}}$ IR aktif modlar ve $2 \mathrm{~A} 1_{\mathrm{u}}$ ve $3 \mathrm{~A} 2_{\mathrm{g}}$ ise ne Raman ne de IR aktif modlardır. Raman spektrumunda gözlenen 378 ve $416 \mathrm{~cm}^{-1}$ pikleri sirasiyla $\mathrm{E}_{\mathrm{g}}$ ve $\mathrm{A} 1_{\mathrm{g}}$ modlarına karşılık gelen karakteristik piklerdir [22, 23]. 


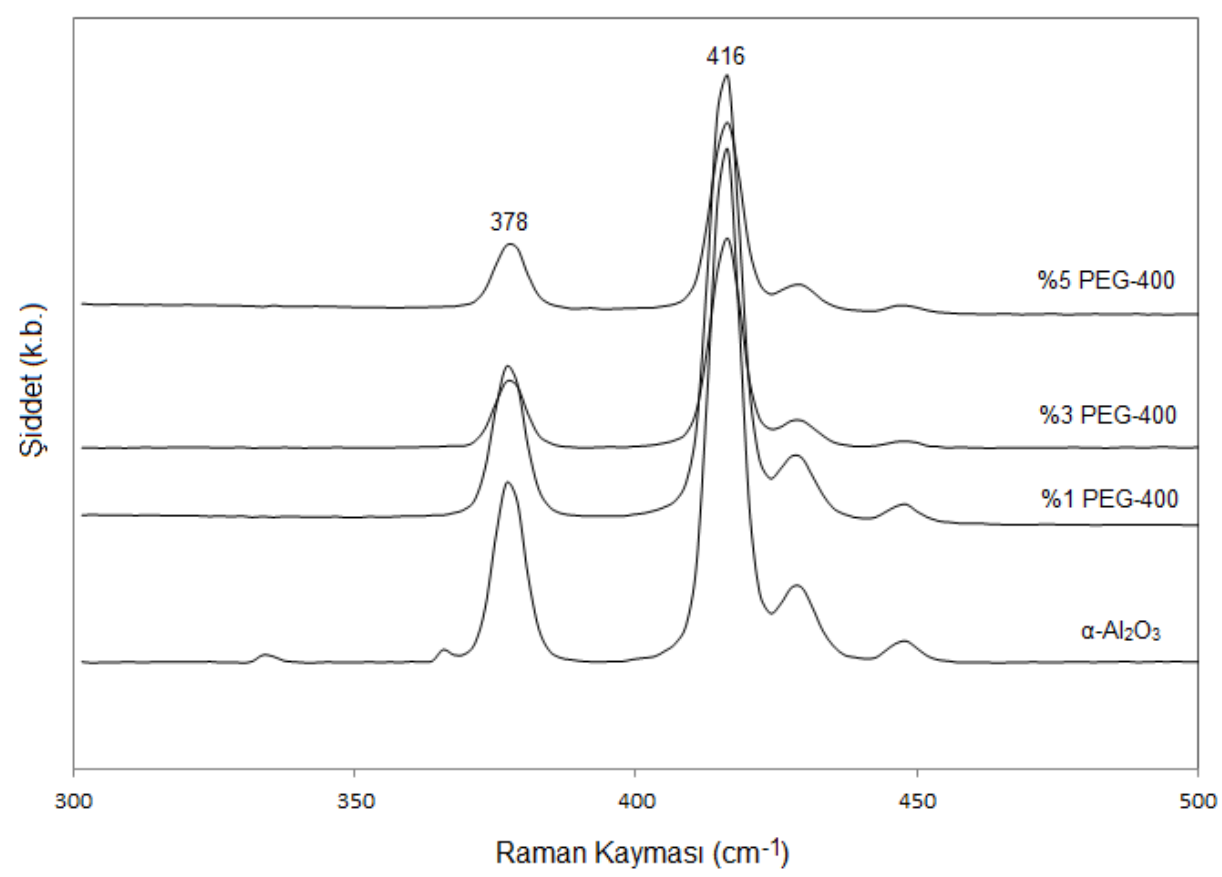

Şekil 3. $\alpha-\mathrm{Al}_{2} \mathrm{O}_{3}$ yaplsina ait Raman spektrumu

Şekil 4, sentezlenen $\alpha-\mathrm{Al}_{2} \mathrm{O}_{3}$ yapılarına ilişkin FTIR spektrumunu vermektedir. Spektrumda $400-1000 \mathrm{~cm}^{-}$ ${ }^{1}$ bölgesinde gözlenen pikler genel olarak Al-O bağlarıyla ilişkilendirilmektedir. Spektruma göre 549, $552,631 \mathrm{~cm}^{-1}$ de gözlenen baskın pikler $\alpha-\mathrm{Al}_{2} \mathrm{O}_{3}$ oktahedral yapısına ait karakteristik piklerdir. Spektrumda 2312 ve $2285 \mathrm{~cm}^{-1}$ civarında gözlenen pikler ise $\mathrm{HCO}_{3}$ grubuna ait titreşim pikleridir. $\mathrm{Bu}$ pikler sentez aşamasında yapıda bulunan ve kalsinasyon sırasında $\mathrm{CO}_{2}$ ve $\mathrm{H}_{2} \mathrm{O}$ vererek bozunan PEG yapısından kaynaklanmaktadır ve yapıda $\mathrm{CO}_{2} \mathrm{ve}_{2} \mathrm{O}$ absorpsiyonu olduğunu göstermektedir [24].

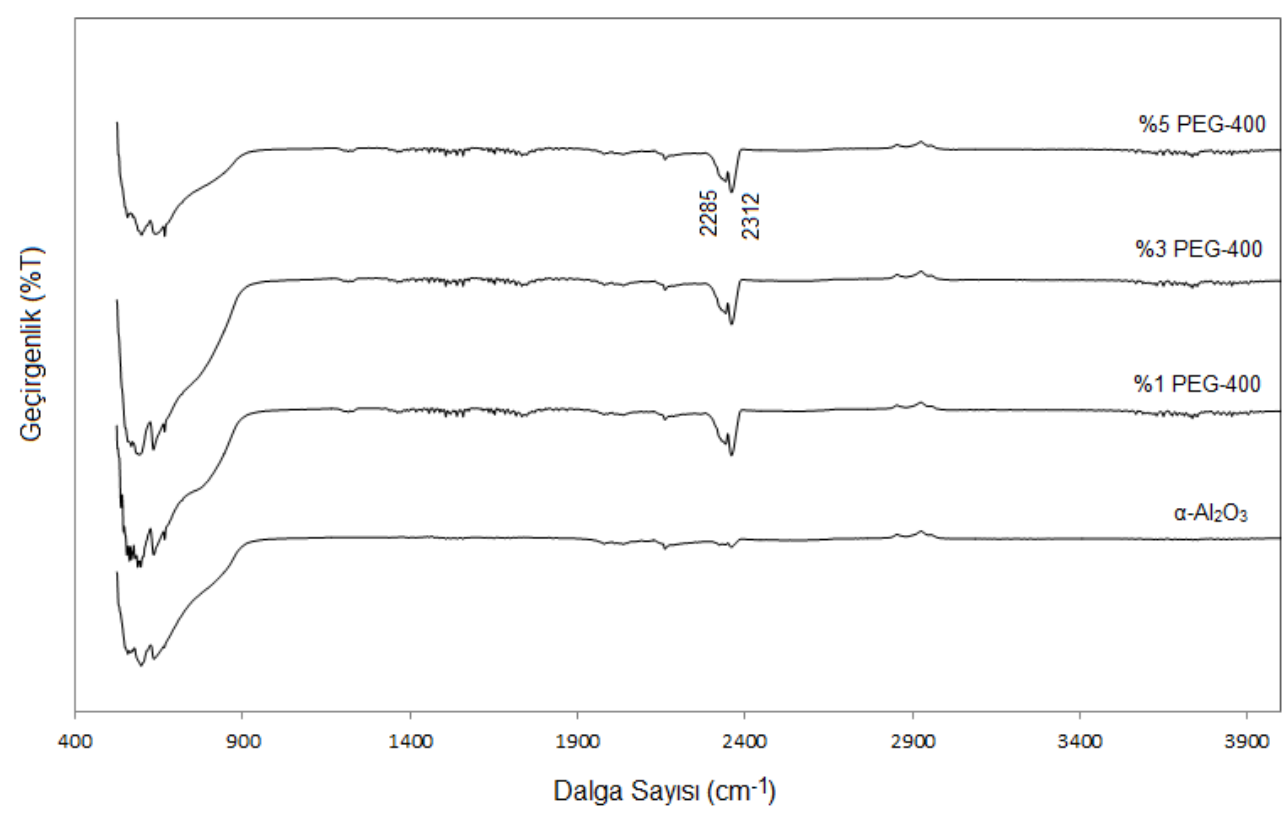

Şekil 4. $\alpha-\mathrm{Al}_{2} \mathrm{O}_{3}$ yapisina ait FTIR spektrumu 
Şekil 5'te gözlenen TGA termogramları kalsinasyon öncesi kurutulan ham ürünler kullanılarak elde edilmiştir. Elde edilen termogramlarda $250^{\circ} \mathrm{C}^{\prime}$ ye kadar gözlenen kütle kayıpları, kurutma sonrası yapıda kalmış muhtemel çözgenden ve yapıya zayıf bağlanmış su moleküllerinin uzaklaşmasından kaynaklanmaktadır. \%1, \%3 ve \%5 PEG-400 katkılı termogramlarda ise katkılama miktarı arttıç̧a kütle kaybının da katkı miktarıyla orantılı olarak arttı̆̆ gözlenmektedir. Bu durumda katkılanan PEG-400 yapısının da aynı sıcaklık bölgesinde bozunarak $\mathrm{CO}_{2}$ ve $\mathrm{H}_{2} \mathrm{O}$ şekline dönüştüğü söylenebilir. Literatürde de alkil zincirlerinin $200^{\circ} \mathrm{C}$ sicaklığın altında tamamen bozunduğu belirtilmiştir [24]. Şekil 4'teki FTIR spektrumunda gözlenen ve $\mathrm{CO}_{2}$ ve $\mathrm{H}_{2} \mathrm{O}$ absorpsiyonundan kaynaklanan 2312 ve $2285 \mathrm{~cm}^{-1}$ piklerinin sebebi de bu bozunmadır. $250^{\circ} \mathrm{C}$ üzerindeki bozunmalar ise bohmit yapısında bulunan $-\mathrm{OH}$ bağlarının yapıdan ayrılmasıyla ilişkilendirilebilir. Yaklaşık $550^{\circ} \mathrm{C}$ 'den sonra, elde edilen bütün yapılar $\mathrm{Al}_{2} \mathrm{O}_{3}$ yapısında ve termal olarak kararlıdır.

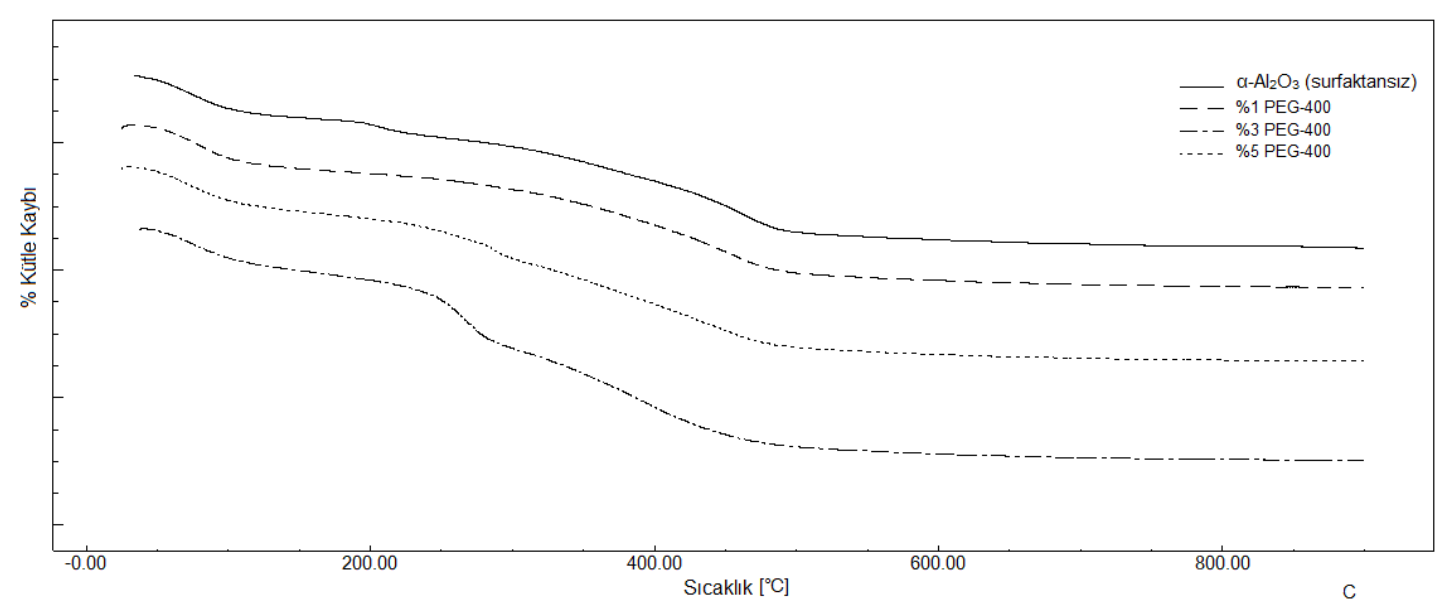

Şekil 5. $\alpha-\mathrm{Al}_{2} \mathrm{O}_{3}$ yapısına ait TGA termogramı

Şekil 6'da kalsine edilmiş PEG-400 katkı1ı (Şekil 6 b-d) ve katkısız (Şekil 6a) sentezlerden elde edilen $\alpha$ $\mathrm{Al}_{2} \mathrm{O}_{3}$ tozlarına ait SEM görüntüleri verilmiştir. Şekil 6a'da görülen katkısız sentezden elde edilen toz, yığın yapıda ve düzensiz morfolojidedir. \%1 PEG-400 katkısıyla elde edilen üründe ise morfolojinin değişmeye başladığı görülmektedir. Katkılama miktarı \%3 oranına çıktığı zaman Şekil6c'de görülen 150$200 \mathrm{~nm}$ boyutlu parçacıklar elde edilmektedir. Katkılama miktarının \%5'e çıkarılması yapıda büyük bir değişikliğe neden olmamaktadır. Reaksiyon ortamında PEG varlığı, alüminyum hidroksit oluşumu aşamasında hidroliz ve kondenzasyonunu engelleyerek daha küçük parçacıkların oluşmasına neden olmaktadır. Bunun nedeni, parçacık yüzeyindeki hidrojen bağı oluşumu ve $\mathrm{Al}^{+3}$ Lewis asidik bölgeleri ile PEG yapısındaki etoksi gruplarında bulunan bazik oksijenlerin koordinasyonu veya elektrostatik etkileşimler olabilir $[25,26]$. Kalkılama miktarının \%5'e çıkarılmasıyla parçacık boyutunda büyük değişikliğin olmamasının sebebi, bahsedilen etkileşimlerde yapıyı değiştirecek kadar büyük farklılık olmaması şeklinde yorumlanabilir. 

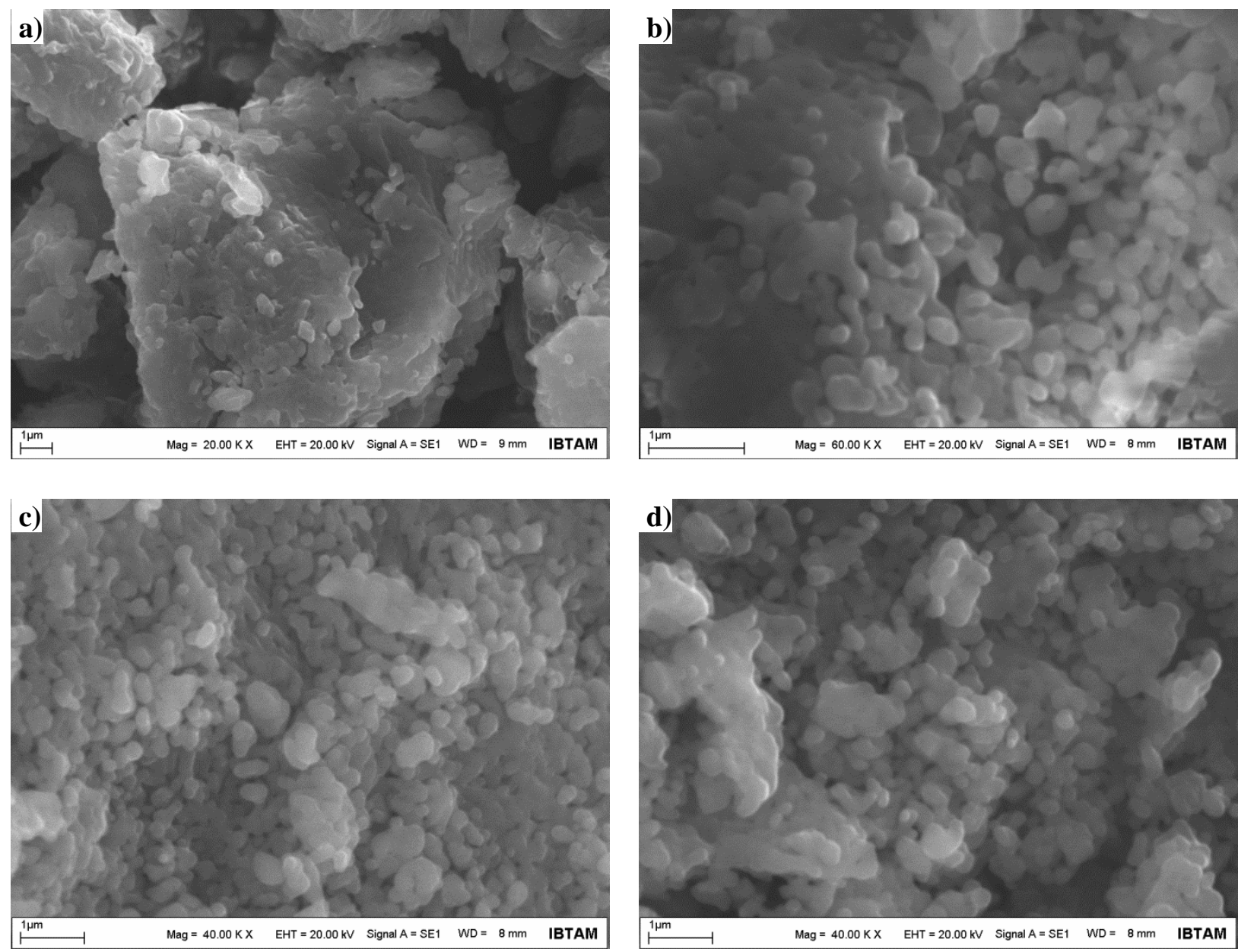

Şekil 6. $\alpha-\mathrm{Al}_{2} \mathrm{O}_{3}$ yapısina ait SEM görüntüleri: a) Katkısız, b) \%1 PEG-400 katkılı, c) \%3 PEG-400 katkll ve d) \%5 PEG-400 katkull sentezlerden elde edilmiş tozlar

\section{TARTIŞMA (DISCUSSION)}

Sonuç olarak, yap1 düzenleyici ajan olarak PEG-400'un kullanıldığg $\alpha-\mathrm{Al}_{2} \mathrm{O}_{3}$ sentezi başarılı şekilde gerçekleştirilmiştir. Çalışma ve elde edilen sonuçlar aşağıdaki gibi özetlenebilir:

I. Kullanılan polimerik düzenleyicinin yapısal olarak parçacıkları sınırlandırması nedeniyle 150-200 $\mathrm{nm}$ boyut aralığında parçacıklar elde edilmiştir.

II. Sentez yöntemi olarak, basit bir teknik olması ve bol miktarda ürün elde edilebilmesi nedeniyle hidrotermal sentez tercih edilmiştir.

III. Sentezlenen ham ürünler $1200^{\circ} \mathrm{C}^{\prime}$ de 3 saat kalsine edilerek alüminanın termal olarak en kararlı fazı olan $\alpha$-alümina fazı elde edilmiştir.

IV. Çalışmada PEG-400 tercih edilmesinin nedeni ucuz ve kolay temin edilebilen bir polimer olmasıdır. Laboratuvar ortamında yapılan sentezlerde her ne kadar elde edilen ürün önemli olsa da, endüstriyel üretimlerde maliyet de bir o kadar önemlidir. Dolayısıyla tercih edilen reaktiflerin ve katk1 maddelerinin maliyetinin de hesaba katılması gerekmektedir. Bu noktadan bakıldığında PEG-400 kullanımı, büyük miktardaki sentezlerde kullanılabilecek ucuz ve etkili bir maddedir. 
V. Alümina endüstride yoğun olarak kullanılan bir maddedir. Kullanım alanlarını ise parçacık boyutu belirlemektedir. Örneğin, polimerik kompozitlerin üretiminde güçlendirici olarak kullanılan alümina katkısının kompozit içerisine homojen dağılması istenir. Parçacık boyutunun küçülmesi homojen dağılımı kolaylaştıracaktır.

VI. Ayrıca anyonik ve katyonik sürfaktanlarla karşılaştırıldığında, bozunma aşamasında inorganik kalıntı bırakmaması nedeniyle PEG-400'ün yapıdan tamamen uzaklaştırılması daha kolaydır.

VII. Çalışmadan elde edilen olumlu sonuçlara göre, daha yüksek molekül kütleli (PEG-1000, PEG-6000 gibi) polimerler kullanıldığında parçacık boyutunun da küçülebileceği değerlendirilmektedir.

\section{TEŞEKKÜR (ACKNOWLEDGMENTS)}

Necmettin Erbakan Üniversitesi, Bilimsel Araştırma Projeleri (BAP) Birimi'ne 181331002 nolu projeyle verdikleri finansal destekten dolayı teşekkür ederiz.

\section{KAYNAKLAR (REFERENCES)}

[1] [1] J. Chandradass, J. H. Yoon, D. S. Bae, Synthesis and characterization of zirconia doped alümina nanopowder by citrate-nitrate process. Materials Science and Engineering A, 473 (2008) 360-364.

[2] Z. X. Sun, T. T. Zheng, Q. B. Bo, M. Du, W. Forsling, Effects of calcination temperature on the pore size and wall crystalline structure of mesoporous alümina. Journal of Colloid and Interface Science 319 (2008) 247-251.

[3] J. Z. Yang, M. H. Fang, Z. H. Huang, X. Z. Hu, Y. G. Liu, H. R. Sun, J. T. Huang, X. C. Li, Solid particle impact erosion of alümina-based refractories at elevated temperatures. Journal of the European Ceramic Society, 32:2 (2012) 283-289.

[4] V. Kir'yanov, S. H. Siddiki, Y. O. Barmenkov, S. Das, D. Dutta, A. Dhar, A. V. Khakhalin, E. M. Sholokhov, N. N. Il'ichev, S. I. Didenko, and M. C. Paul, Hafnia-yttria-alümina-silica based optical fibers with diminished mid-IR $(>2 \mu \mathrm{m})$ loss. Optical Materials Express, 7:7 (2017) 2511-2518.

[5] Levin, D. Brandon, Metastable alümina polymorphs: crystal structure andtransition sequences, J. Am. Ceram. Soc., 81 (1998) 1995-2012.

[6] M. T. Ravanchi, M. R. Fard, S. Fadaeerayeni, F. Yaripour, Effect of Calcination Conditions on Crystalline Structure and Pore Size Distribution for a Mesoporous Alümina. Journal Chemical Engineering Communications, 202:4 (2015) 493-499.

[7] R. K. Dwivedi, G. Gowda. Thermal stability of aluminium oxides prepared from gel. J. Mater. Sci. Lett., 4 (1985) 331-334.

[8] Saraswati, V., Rao, G. V. N., and Rao, G. V. R. (1987). Structural evolution in alümina gel, J. Mater. Sci., 22, 2529-2534.

[9] T. Assih, A. Ayral, M. Abenoza, J. Phalippou,. Raman study of alümina gels. J. Mater. Sci., 23 (1988) 3326-3331.

[10] R. Ozao, M. Ochiai, H. Yoshida, Y. Ichimura, T. Inada,. Preparation of $\gamma$-alümina membranes from sulphuric electrolyte anodic alümina and its transition to $\alpha$-alümina. J. Therm. Anal. Calorim, 64 (2001) 923-932.

[11] K. Lu, Theoretical analysis of colloidal interaction energy in nanoparticle suspensions. Ceramics International 34: 6 (2008) 1551-1556.

[12] J.S. Forrester, H.J. Goodshaw, E.H. Kisi, G.J. Suaning, J.S. Zobec, Effect of Mechanical Milling on the Sintering Behaviour of Alümina. Aust. Ceram. Soc. 44:1 (2008) 47-52. 
[13] F. Mirjalili, M. Hasmaliza, A. L. Chuah, Size-controlled synthesis of nano $\alpha$-alümina particles through the sol-gel method. Ceramics International 36 (2010) 1253-1257.

[14] P. K. Panda, V. A. Jaleel, S. Usha Devi, Hydrothermal synthesis of boehmite and $\alpha$-alümina from Bayer's alümina trihydrate. J Mater. Sci., 41 (2006) 8386-8389.

[15] R. Lafficher, M. Dignea, F. Salvatoria, M. Bouallega, D. Colsonb, F. Puel, Development of new alümina precipitation routes for catalysis applications. Journal of Crystal Growth, 468 (2017) 526-530.

[16] T. E. Bell, J. M. Gonz'alez-Carballo, R. P. Tooze, L. Torrente-Murciano, g- $\mathrm{Al}_{2} \mathrm{O}_{3}$ nanorods with tuneable dimensions a mechanistic understanding of their hydrothermal synthesis. RSC Adv., 7 (2017) 22369-22377.

[17] S. Bhaduri, E. Zhou, S.B. Bhaduri, Auto ignition processing of nanocrystalline a- $\mathrm{Al}_{2} \mathrm{O}_{3}$. Nanostruct. Mater. $7: 5$ (1996) 487-496.

[18] J. Li, Y. Pan, C. Xiang, Q. Ge, J. Guo, Low temperature synthesis of ultrafine a- $\mathrm{Al}_{2} \mathrm{O}_{3}$ powder by a simple aqueous sol-gel process. Ceramics International 32 (2006) 587-591.

[19] S. Vural, Nanometrik Boyuttaki Metal Oksit Sollerinin Olusumlari, Yapisal Kontrolü ve Fizikokimyasal Özelliklerinin Arastirilmasi, Inonu Universitesi, Malatya, 2007.

[20] A. H. Lu, E. L. Salabas, F. Schüth, Magnetic Nanoparticles: Synthesis, Protection, Functionalization, and Application. Angew. Chem. Int. Ed., 46 (2007) 1222 - 1244.

[21] G. Li, Y. Sun, X. Li, Y. Liu, Adsorption of Congo red from water with spindle-like boehmite: the role of lattice plane (020). RSC Adv., 6 (2016) 11855-11862.

[22] J. Gangwar, B. K. Gupta, S. K. Tripathi, A. K. Srivastav, Phase dependent thermal and spectroscopic responses of $\mathrm{Al}_{2} \mathrm{O}_{3}$ nanostructures with different morphogenesis. Nanoscale, $\mathrm{m} 7$ (2015) 13313-13344.

[23] G. Pezzotti, W. Zhu, Resolving stress tensor components in space from polarized Raman spectra: polycrystalline alümina. Phys. Chem. Chem. Phys., 17 (2015) 2608-2627.

[24] L. Sicard, P.L. Llewellyn, J. Patarin, F. Kolenda, Investigation of the mechanism of the surfactant removal from a mesoporous alümina prepared in the presence of sodium dodecylsulfate. Micro. Meso. Mater. 44-45 (2001) 195- 201.

[25] Z.-X. Sun, T.-T. Zheng, Q.-B. Bo, M. Du, W. Forsling, Effects of calcination temperature on the pore size and wall crystalline structure of mesoporous alümina, Journal of Colloid and Interface Science, 319 (2008) 247-251.

[26] L. Saravanan, S. Subramanian, Surface chemical studies on the competitive adsorption of poly(ethylene glycol) and ammonium poly(methacrylate) onto alümina, Journal of Colloid and Interface Science, 284 (2005) 363-377. 